\title{
One-Hand Engineering Effectiveness to the Reduction of the Number of Bloodage in Third-Three Phase of Certificate Mother in Maulidya Husada Clinic, Karangploso Sub-District, Malang District
}

\author{
Herwati Herwati ${ }^{1}$, Rahmania \\ Ambarika $^{2}$, Indasah Indasah ${ }^{3}$ \\ ${ }^{1}$ Health Office of Malang \\ Regency \\ ${ }^{2}$ Institute of Health Sciences \\ Strada Indonesia, Kediri \\ ${ }^{3}$ Institute of Health Sciences \\ Strada Indonesia, Kediri \\ Email: \\ herwati17@gmail.com
}

Received : May $7^{\text {th }} 2021$

Accepted : May 10 2021

Published : May $20^{\text {th }} 2021$

\begin{abstract}
The maternal mortality rate in Indonesia in 2015 was 305 out of 100,000 live births according to the Ministry of Health of the Republic of Indonesia. Postpartum hemorrhage is bleeding that occurs after delivery (delivery), as much as $500 \mathrm{ml}$ in vaginal delivery or more than $1000 \mathrm{ml}$ in cesarean section. This study aims to determine the effectiveness of the one-hand technique in reducing the amount of bleeding compared to the two-hand technique that has been used in third-stage active management. This study is an experimental quantitative study to compare the one-hand technique in third-stage active management versus the two-hand technique. The population was taken from all pregnant women who gave birth in the delivery room of KRI Maulidya Husada within three months. The number of samples in this study were 36 people, namely: 18 people using the one-hand technique that met the inclusion criteria and 18 people using the two hand technique who met the inclusion criteria. In this study, it is known that almost all respondents with spontaneous labor who were given the one-hand technique experienced bleeding less than $250 \mathrm{cc}$, namely $61 \%$ and the two-hand technique treatment experienced bleeding more than $250 \mathrm{cc}$, namely $39 \%$
\end{abstract}

Keywords: Management, one-hand, two-hand, bleeding, engineering

Copyright @ 2021 IIK STRADA Indonesia All right reserved.

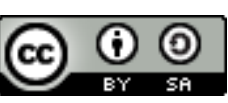

This is an open-acces article distributed under the terms of the Creative Commons Attribution-ShareAlike 4.0 International License. 


\section{INTRODUCTION}

Maternal mortality can occur as a result of complications during and after pregnancy and during delivery. As many as $80 \%$ of maternal deaths in the world are caused by heavy bleeding (most often bleeding after childbirth), infection, high blood pressure during pregnancy (preeclampsia and eclampsia) and unsafe abortion (WHO, 2005). Postpartum hemorrhage is bleeding that occurs after delivery (delivery), as much as $500 \mathrm{ml}$ in vaginal delivery or more than $1000 \mathrm{ml}$ in cesarean section (Coker \& Oliver, 2006).

Other factors associated with labor and increased blood loss are episiotomy, caesarean section, and prolonged labor (Stones, 1993). Most cases of post-partum hemorrhage (PPH) occur during the third stage of labor. During this time, the uterine muscles contract and the placenta begins to separate from the uterine wall. The amount of blood lost depends on how quickly this happens. Third stage labor usually lasts between 5 and 15 minutes (Bulgaho, 2001). In fact, early PPH can often be treated with basic obstetric care, however delays can lead to further complications that require comprehensive emergency obstetric care.

\section{MATERIALS AND METHODS}

Ethical clearance approved by Health Research Ethics Committe Institute of Health Sciences STRADA Indonesia No: 1648/KEPK/XI/2019. Third stage active management is a policy that requires prophylactic uterotonic administration as a preventive measure to reduce the risk of postpartum hemorrhage regardless of maternal obstetric risk status. Third stage active management policies usually include the routine administration of uterotonic agents, either intravenously, intramuscularly or orally. This administration is performed in conjunction with umbilical cord clamping immediately after birth of the baby and delivery of the placenta using controlled cord traction. If studies show that the mother is also at high risk of postpartum hemorrhage (eg, multiple births, grand multiparous), a larger uteronic dose prophylactic infusion dissolved in intravenous fluids can be given for several hours after birth. It is also considered part of the active management policy. The active management of the third stage is the policy for managing the third stage of labor in the world (Myles, 2011).

\section{RESULTS}

Efforts to increase the achievement of the program to reduce maternal mortality, especially those caused by postpartum hemorrhage, include increasing the capacity of health workers with training in normal delivery care, increasing the capacity of health workers in handling maternal emergencies, improving infrastructure and referral systems, providing supporting facilities and infrastructure, and equal distribution of health personnel. However, there are obstacles in achieving the program, namely the competence of health workers is still low: untrained or trained health workers do not implement the acquired competencies, the referral system is not optimal, the distribution of health workers is uneven and infrastructure is inadequate, and services are not up to standard (Wardani, 2017).

Another study mentions a comparison of active and physiological third-stage management in relation to placental bleeding and removal. Active management of the third stage of labor consists of interventions used to accelerate the release of the placenta by increasing uterine contractions and to prevent postpartum bleeding and avoid uterine atony. Meanwhile, conservative/physiological management is to wait for signs that the placenta has separated from the uterine wall (the umbilical cord increases in length, the uterus is globular and bursts suddenly and briefly), and allows the placenta to be born spontaneously (Cardoso et al, 2005).

Table 1. Three active management proved to be more effective in reducing postpartum hemorrhage 


\begin{tabular}{llll}
\hline \multicolumn{1}{c}{ Factors } & \multicolumn{1}{c}{ Study } & Active & $\begin{array}{c}\text { Management } \\
\text { Physiologic }\end{array}$ \\
\hline PPH & Bristo & $15.9 \%$ & $17.9 \%$ \\
& Hinchingbrooke & $6.8 \%$ & $16.5 \%$ \\
Average length of the third stage & Bristo & 5 minutes & 15 minutes \\
of labor & Hinchingbrooke & 8 minutes & 15 minutes \\
Third stage of labor longer than & Bristo & $2.9 \%$ & $26 \%$ \\
30 minutes & Hinchingbrooke & $3.3 \%$ & $16.4 \%$ \\
Blood transfusion needed & Bristo & $2.1 \%$ & $5.6 \%$ \\
& Hinchingbrooke & $0.5 \%$ & $2.6 \%$ \\
Additional uterotonic drugs & Bristo & $0.5 \%$ & $2.6 \%$ \\
needed to manage PPH & Hinchingbrooke & $3.2 \%$ & $21.1 \%$ \\
\hline
\end{tabular}

\section{STATISTICAL TEST RESULTS}

\section{Placenta Data Statistical Test Results on One Hand and Two Hand Techniques}

a. Testing the Difference in the Amount of Bleeding Using the One Hand and Two Hand Techniques for Third Stage Active Maternity Women.

In this study, the observed variable was the amount of bleeding in the third stage of active management using one-hand and two-hand techniques in the subjects studied.

Table 2. Amount of Bleeding (cc) in Third Stage Active Management

\begin{tabular}{ccc}
\hline Name & Technique One Hand & Technic Two Hand \\
\hline R1 & 100 & 200 \\
R2 & 75 & 200 \\
R3 & 100 & 250 \\
R4 & 150 & 200 \\
R5 & 100 & 175 \\
R6 & 75 & 200 \\
R7 & 75 & 250 \\
R8 & 100 & 200 \\
R9 & 100 & 175 \\
R10 & 150 & 175 \\
R11 & 75 & 250 \\
R12 & 75 & 250 \\
R13 & 75 & 250 \\
R14 & 150 & 200 \\
R15 & 100 & 250 \\
R16 & 75 & 200 \\
R17 & 100 & 200 \\
R18 & 100 & 250 \\
Total & 1775 & 3875 \\
\hline
\end{tabular}

Using the one-hand technique, bleeding was found to range from 175-250 $\mathrm{cc}$ in the subjects studied. Whereas in the two-hand technique, bleeding was found to be $75-100 \mathrm{cc}$ in the studied subjects. When compared to this study, bleeding was found to be more frequent in the two-hand technique. There is no definite source regarding the difference in one-hand and two-hand techniques.

b. Average Amount of Bleeding Using One Hand and Two Hand Techniques for Third Stage Active Maternity Women 
The general description of the mean and standard deviation of the amount of bleeding in the one hand technique group and the two hand group can be seen in the following figure.

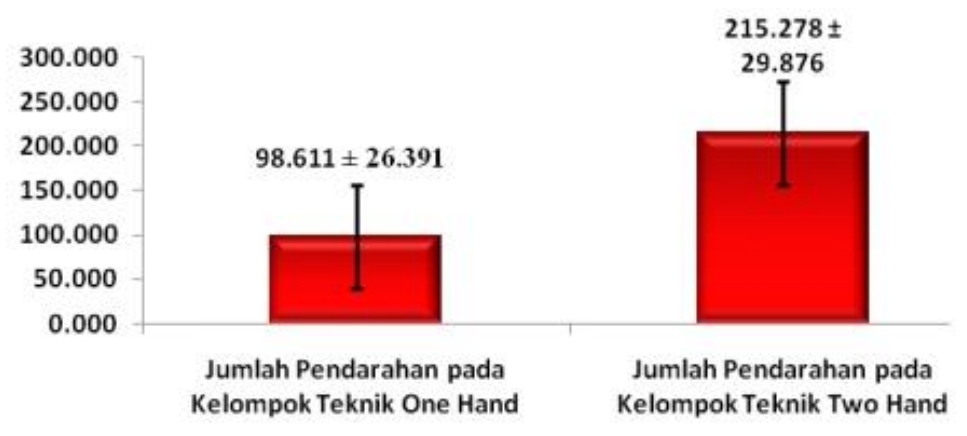

Figure 1. Average Bleeding in One-Hand and Two-Hand Techniques

The picture above informs that the average amount of bleeding in the group of women who gave birth using the one hand technique at the Maulidya Husada clinic, Karangploso District, Malang Regency was 98,611 $\pm 26,391 \mathrm{CC}$. Then the average amount of bleeding in the group of women who gave birth using the two hand technique at the Maulidya Husada clinic, Karangploso District, Malang Regency was 215,278 $\pm 29,876$. Based on the descriptive analysis of the two groups, it can be seen that the average amount of bleeding in the group of women who gave birth using the one hand technique was lower than the average amount of bleeding in the group of women who used the two hand technique.

\section{c. Normality and Homogeneity Test of Bleeding Observation Results in One Hand and Two Hand Techniques}

Table 3. Normality test of bleeding data with one hand and two hand techniques

\begin{tabular}{|r|r|r|r|r|r|r|r|}
\hline \multirow{2}{*}{} & \multirow{3}{*}{} & \multicolumn{4}{|c|}{ Kolmogorov-Smirnox } & \multicolumn{3}{|c|}{ Shapiro-Wilk } \\
\cline { 3 - 8 } & Kelas & Statistic & \multicolumn{1}{c|}{ df } & \multicolumn{1}{c|}{ Sig. } & Statistic & \multicolumn{1}{c|}{ df } & \multicolumn{1}{c|}{ Sig. } \\
\hline \multirow{2}{*}{ Pendaraban } & One-Hand & .312 & 18 & .000 & .751 & 18 & .000 \\
& Two-Hand & .307 & 18 & .000 & .775 & 18 & .001 \\
\hline
\end{tabular}

\section{a. Lilliefors Significance Correction}

The normality test of the bleeding observation data in the one hand and two hand techniques using Saphiro-Wilk, shows that the Saphiro-Wilk statistical value is 0.751 in the one hand technique, with a significance value of 0.000 . While in the two hand technique, the statistical value of Saphiro-Wilk is 0.775 , with a significance value of 0.001 . From these data it can be seen that the significance value $<0.05$, so it can be decided that the data is not normally distributed. 
Table 4. Homogeneity test of bleeding data using one hand and two hand techniques Test of Homogeneity of Variance

\begin{tabular}{|ll|r|r|r|r|}
\hline & Levene Statistic & \multicolumn{1}{c|}{ df1 } & \multicolumn{1}{c|}{ df2 } & \multicolumn{1}{c|}{ Sig. } \\
\hline Pendarahan & Based on Mean & 2.924 & 1 & 34 & .096 \\
& Based on Median & .615 & 1 & 34 & .438 \\
& Based on Median and with & .615 & 1 & 32.468 & .438 \\
& adjusted df & & & \\
& Based on trimmed mean & 2.832 & 1 & 34 & .102 \\
\hline
\end{tabular}

The homogeneity test of the bleeding observation data on the one hand and two hand techniques used the Levene test, showing that the Levene statistical value was 2.924 , with a significance value of 0.096 . From these data, it can be seen that the significance value is> 0.05 , so that it can be decided that the data has a homogeneous variant.

\section{d. Data Hypothesis Testing The amount of bleeding using the One Hand and Two Hand Technique for Third Stage Active Maternity Women}

Testing the difference in the amount of bleeding using one hand and two hand techniques for mothers in the active phase of the third stage of labor was carried out using Mann Whitney with the following hypothesis :

H0: There is an insignificant difference in the amount of bleeding using the one hand and two hand techniques for mothers in the active phase of the third stage of labor.

H1: There is a significant difference in the amount of bleeding using the one-hand and twohand techniques in mothers of third stage active labor.

The test criterion states that if the probability $\leq \alpha(5 \%)$ table then $\mathrm{H} 0$ is rejected, so it can be stated that there is a significant difference in the amount of bleeding using the one hand and two hand techniques in mothers with stage three active phase. The results of testing the difference in the amount of bleeding using one-hand and two-hand techniques for mothers in the third stage of active labor can be seen in the following table:

Table 4.19 Test for different amounts of bleeding in the technique One-Hand and Two-Hand

\begin{tabular}{lccc}
\hline \multicolumn{1}{c}{ Placenta } & Average & Z-Statistics & Probability \\
\hline Technique One Hand & 98.611 & -5.223 & 0.000 \\
Technique Two Hand & 215.876 & & \\
\hline
\end{tabular}

Based on the test results listed in the table, it can be seen that the $\mathrm{Z}$ test statistic generated is $-5,223$ with a probability of 0.000 . This means the probability <level of significance $(\mathrm{a}=$ $5 \%$ ), so that $\mathrm{HO}$ is rejected. Thus it can be stated that there is a significant difference in the amount of bleeding using the one-hand and two-hand techniques for mothers in the active phase of the third stage of labor.

Judging from the mean value, the average amount of bleeding using the one hand technique in stage three active phase mothers was smaller than the average amount of bleeding using the two hand technique in stage three active phase mothers. This means that the average amount of bleeding using the one hand technique for mothers in the active phase of the third 
stage of labor is lower than the average amount of bleeding using the two hand technique for mothers in the active phase of the third stage of labor.

\section{DISCUSSION}

\section{Bleeding incidence in third stage active management}

It can be seen that the labor process is influenced by several factors, one of which is age, from 36 respondents, the results of the study showed that respondents who experienced spontaneous labor during the third stage of active management with the one hand technique were included in the 20-35 year age group, namely $83 \%$ (30 people ).

Apart from age, the results of data processing show that parity also affects the labor process and post partum hemorrhage in third stage active management with the one hand technique. Respondents, including primiparous, mostly underwent spontaneous labor, active management of the third stage with the one hand technique, as many as 53\% (19 people). And most of them did not experience post partum hemorrhage, as many as $61 \%$ (22 people).

Likewise, from the risk of bleeding spontaneous labor in the third stage of active management with the one-hand technique, the results of the study showed that most of the respondents who were $25-35$ years old did not experience bleeding, namely $83 \%$ (30 people).

\section{The effectiveness of one hand techniques in third stage active management}

In this study, it was found that the average amount of bleeding was 75-100 $\mathrm{cc}$ in third-stage active management with the one-hand technique was smaller, namely $61 \%$ ( 22 people).

A common cause of severe early postpartum bleeding (which occurs 24 hours after delivery) is uterine atony (failure of the uterus to contract properly after delivery). Retained placenta, vaginal tearing and uterine sagging or inversion are also causes of postpartum bleeding. Active management stage III has been carried out routinely in the management of stage III labor. However, there is controversy because it contradicts the philosophy of midwifery and not all women have the same values and philosophy. In some women want a natural delivery without any intervention, including administration of drugs. Based on the quantitative analysis in this study, as many as $15(100 \%)$ journals in conclusion suggest using stage III active management for prevention of postpartum hemorrhage. controlled cord tension with the right hand and gentle pressure on the sympisis with the left hand.

3. The Effectiveness of Two Hand Technique In Third Stage Active Management

In this study, it was found that the amount of bleeding in the third stage of active delivery using the two-hand technique was more in the range of 175-250 cc. In 18 subjects studied, $78 \%$ (14 people) experienced the amount of bleeding. This is consistent with the investigators' suspicion that the two-hand technique in third-stage active management was less effective in reducing the amount of bleeding.

4. The Difference between The One Hand Technique and the Third Stage Active Management with The Two Hand Technique on the Incidence of Post Partum Hemorrhage 
No sources have yet compared these two techniques in third stage active management. In this study, it was found that there was a significant difference in the amount of bleeding using the one hand and two hand techniques in mothers who gave birth in third stage active management with a probability of 0.000 . Judging from the average value, the average amount of bleeding using the one hand technique in three-stage active management mothers was smaller, namely $61 \%$ (22 people) than the average amount of bleeding using the two hand technique in active management mothers third stage is $39 \%$ (14 people). This means that the average amount of bleeding using the one hand technique in third stage active management mothers is lower than the average amount of bleeding using the two hand technique in third stage active management mothers.

Efforts to increase the achievement of the program to reduce maternal mortality, especially those caused by postpartum hemorrhage, include increasing the capacity of health workers with training in normal delivery care, increasing the capacity of health workers in handling maternal emergencies, improving infrastructure and referral systems, providing supporting facilities and infrastructure, and equal distribution of health personnel. However, there are obstacles in achieving the program, namely the competence of health workers is still low: untrained or trained health workers do not implement the acquired competencies, the referral system is not optimal, the distribution of health workers is uneven and infrastructure is inadequate, and services are not up to standard (Wardani, 2017).

Another study mentioned the comparison of active and physiological third-stage management in relation to placental bleeding and removal. Active management of the third stage of labor consists of interventions used to accelerate the release of the placenta by increasing uterine contractions and to prevent postpartum bleeding and avoid uterine atony. Meanwhile, conservative / physiological management is to wait for signs that the placenta has separated from the uterine wall (the umbilical cord increases in length, the uterus is globular and bursts suddenly and briefly), and allows the placenta to be born spontaneously (Cardoso et al, 2005).

\section{CONCLUSION}

Seminars or training for use From the results of research that was carried out at the Maulidya Husada Inpatient Clinic from 25 November 2019 to 25 January 2020, the following conclusions were drawn:

1. The one-hand technique has a better effect on placenta removal on stage III active management than using the two-hand technique.

2. One-hand technique is effective in reducing bleeding compared with the two-hand technique for inpartum mothers in active management stage III.

3. One-hand technique has an effect on the condition of 2 hours post partum in stage III active management of inpartum mothers by reducing the incidence of bleeding. 


\section{ACKNOWLEDGMENT AND CONFLICT OF INTEREST}

Based on these conclusions by paying attention to the benefits and limitations of the study, the researchers provide the following suggestions:

\section{For midwives or nurses at the research place}

It is necessary to improve the quality of service, especially in terms of safe delivery, especially when implementing modified APN with one-hand techniques, it is hoped that close observation is made so that the bleeding incidence rate can be kept as low as possible.

\section{For the clinic where the research is}

It is necessary to make a procedure for normal delivery with modifications to MAK 3, namely the help step using one-hand techniques and postpartum hemorrhage procedures and often reviewing when renewal is needed. It is necessary to increase knowledge so that midwives or nurses in the delivery room can more quickly detect any complications or dangers in childbirth so that it can reduce the incidence of bleeding

\section{For further researchers}

In the data analysis process, it was found that the incident data for 2 hours postpartum between the one-hand and two-hand technique groups was different but not significant. Therefore, it is hoped that further researchers can conduct further research by focusing more on factors that play a role in causing postpartum hemorrhage, such as the quality of uterine contractions, the incidence of uterine fundal height, and the incidence of bladder.

\section{REFERENCES}

Bulgaho, A. Misoprostol for prevention of postpartum hemorrhage. Int J Ginaecol Obstet. 2001. 73 : 1-6.

Coker A, Oliver R. Definitions and classifications (B-Lynch C, Keith L, Lalonde A, Karoshi M, editors). A Textbook of Postpartum Hemorrhage . United Kingdom: Sapiens Publishing; 2006. Hal.130.

Myles. 2011. Buku Ajar Bidan. Jakarta: EGC 499-500

Media Indonesia. (2016). Angka Kematian Ibu Masih Tinggi. Diakses pada tanggal 18 Oktober 2019 di http://mediaindonesia.com/read/detail/83701-angka-kematian-ibu-masih-tinggi-1

Stones, R.W. 1993. Risk factors for major obstetric haemorrhage. Eur J Obstet Gynecol Reprod Biol. 48 : 15-18.

Wardani, PK. 2017. Faktor-faktor yang mempengaruhi perdarahan pasca persalinan. Aisyah: Jurnal Ilmu Kesehatan 2 (1);51-60.

World Health Organization (WHO). (2004). Maternal Mortality Ratio. Diakses pada tanggal 20 Oktober 2019 di http://www.who.int/healthinfo/statistics/indmaterna lmortality/en/.

World Health Organization (WHO). (2014). Maternal Mortality. Diakses pada tanggal 20 Oktober 2019 di http://www.who.int/mediacentre/factsheets/fs348/e n/.

World Health Organization. 2005. Guiding principles on feeding nonbreastfed children 6 to 24 months of age. Geneva: World Health Organization. 